\title{
Patient Reported Improvement After Patch Testing and Allergen Avoidance Counseling: A Retrospective Analysis
}

Meredith S. Steuer · Nina C. Botto

Received: May 2, 2018 / Published online: July 9, 2018

(C) The Author(s) 2018

\begin{abstract}
Introduction: Our objectives were to assess patient-reported improvement after patch testing at the 2-3-month follow-up visit in patients referred for patch testing with relevant positive patch test reactions at the University of California, San Francisco.

Methods: Cross-sectional analyses of patients patch tested between 2013 and 2016 who returned for a follow-up visit approximately 2-3 months after patch testing. We examined positive patch test results considered of definite, probable or possible relevance to the patient's eczematous eruptions. Patients reported improvement after patch testing as a percentage: $0-100 \%$. Patients were categorized into four groups: (1) those that reported no improvement or worsened, (2) those that reported $>0 \%$ and $\leq$ $60 \%$ improvement, (3) those that reported $>$ $60 \%$ but $<100 \%$ improvement and (4) those that reported $100 \%$ improvement. Secondary
\end{abstract}

Enhanced digital features To view enhanced digital features for this article go to https://doi.org/10.6084/ m9.figshare.6682958.

\section{S. Steuer}

San Francisco School of Medicine, University of California, San Francisco, CA, USA

N. C. Botto $(\square)$

Department of Dermatology, University of

California, San Francisco, San Francisco, CA, USA

e-mail: Nina.botto@ucsf.edu measures included the association of allergens, gender, age and location of the rash.

Results: The majority (81\%) of patients seen at follow-up reported improvement after patch testing. Women reported more improvement than men with statistical significance. Notably, there does not appear to be a statistically significant relationship in patient-reported improvement and age, atopy, strength of a the patient's positive reactions, number of positive reactions and follow-up time or with potential systemic contact allergens (i.e., balsam of Peru, nickel, chrome and cobalt).

Conclusion: We find the large percentage of patients that self-report global benefit from patch testing encouraging, as we believe this to be a powerful measure of disease and symptom activity, as well as quality of life. The gender differences we found contradict the previous literature.

Keywords: ACD; Allergen; Allergic contact dermatitis; Global assessment; Patch testing; Patient-reported improvement; Quality of life

\section{INTRODUCTION}

The benefits of using patient-reported metrics have been extensively supported in the medical literature in a wide range of fields. In atopic dermatitis, patients' own assessments of their quality of life often cannot be directly 
correlated with the physical extent of their disease, suggesting that physicians cannot accurately determine how patients feel [1]. Physician assessment of a patient's quality of life is variable, subjective and often inaccurate. There are increasingly more data to suggest that patients' experiences of their disease and treatment differ from their providers' views of their respective disease and treatment. For instance, Linos et al. recently found that when patients were asked if they had experienced any complications from an in-office procedure to treat a non-melanoma skin cancer, they sometimes named problems not documented by medical providers in their charts [2].

Therefore, we believe patients' own assessment must be solicited to reliably and accurately measure patient-perceived benefit and improvement or worsening of disease as well as to truly understand the patient experience [3]. Dermatology literature supports the clear effects allergic contact dermatitis (ACD) has on patients' emotions, function and quality of life, further arguing for gathering patient-generated data [4]. Moreover, patch testing, the gold standard in diagnosing ACD, has demonstrated quality of life benefit, as measured by the Dermatology-Specific Quality of Life (QoL) index [5-7]. Nevertheless, patients' subjective impression and global assessment of their clinical status after patch testing has not been studied outside the realm of QoL tools, which can be lengthy and difficult to implement. Asking patients for their own global assessment of their disease has inherent validity and precedents in the skin disease literature $[8,9]$. In addition, currently, only data from two ACD-specific QoL tools exist, one of which only assessed patients with fragrance allergies and one that was used solely on a population of Italian patients without validation data. A review of the literature suggests that more general skin QoL tools may not pick up on the specific impacts ACD has on patients' experience [10]. Therefore, asking patients for their own assessments of global improvement or worsening without using a validated tool can provide important insight into patient benefit and improvement [2], especially as an exploratory study before developing a validated ACD-specific QoL tool looking at patch test patients in this country. Furthermore, despite the significant number of patients affected by ACD, limited data exist regarding the impact of ACD on patients' lives and their improvement after patch testing and follow-up.

Some research has been done on predictive factors of QoL in patients with ACD with conflicting results. In general, age, sex and diagnosis of eczema do not seem to impact QoL outcomes [11]. However, proximity to retirement and diagnosis of atopic dermatitis have correlated with superior patient-reported outcomes in some studies [12], and female gender has previously predicted inferior outcomes [4].

In this pilot study, we investigate patients' self-reported global improvement after patch testing and allergen avoidance counseling and examine associated factors such as the gender, atopy and allergen profile.

\section{METHODS}

The purpose of this study was to determine the number of patients who self-reported their global experience and benefit, or lack thereof, after patch testing and allergen avoidance counseling. We also examined the relationship between patient-reported improvement and duration of the rash, gender, age and allergen profile among patients patch tested and seen for follow-up at UCSF between 2013 and 2016. We did not use any investigator-reported measures, such as body surface area (BSA).

The allergen avoidance counseling involved (1) avoidance strategies and (2) a customized document or smartphone application listing safe products, based on the patients' individual allergic reactions, to use through the American Contact Dermatitis Society's Contact Allergen Management Program (CAMP) database. Patients were counseled on sources of allergens identified in their products or environment as well as potential sources of exposure and strategies for avoidance. The average amount of time spent counseling patients was $30 \mathrm{~min}$, although the durations ranged from 20 to $50 \mathrm{~min}$, with patients with more allergens requiring more counseling. Patients also often continued their topical corticosteroids as 
maintenance after patch testing. No new treatments were initiated.

The University of California, San Francisco Institute on Human Research, approved the analysis of these data. Between 2013 and 2016, 52 of the 378 patients patch tested were seen in follow-up at an approximate mean time of 2 months. Methods of patch testing and final diagnoses were determined according to standard published methods [13-15]. Data collected included patient-reported improvement (as a percentage, with $100 \%$ meaning complete improvement) or worsening as well as history of background eczema, positive patch test reactions, time between patch test reading and follow-up, and whether the patient returned for multiple follow-ups.

At follow-up, patients were asked to describe, as a global assessment of their experience after patch testing, whether they had worsened or improved. If they noted improvement at the time of the follow-up visit, they were asked to describe that improvement giving a self-reported rating on a scale of 1 to $100 \%$. If they reported no change or worsening, they were recorded as having no improvement or zero.

Patients were categorized into four groups: (1) those that reported no improvement or worsened, (2) those that reported $>0 \%$ and $\leq$ $60 \%$ improvement, (3) those that reported $>$ $60 \%$ but $<100 \%$ improvement and (4) those that reported $100 \%$ improvement. Upon review of the data with our statistician, we identified four clear clusters of results, which determined our numerical cutoffs, as described above, for each group.

All data were collected from the electronic medical record and entered into an Excel database. The different categories' data were compared using a Fisher exact test or a KruskalWallis test. $P \leq 0.05$ were considered statistically significant.

\section{Compliance with Ethics Guidelines}

All procedures performed in studies involving human participants were in accordance with the ethical standards of the institutional and/or national research committee and with the 1964
Helsinki Declaration and its later amendments or comparable ethical standards. Informed consent was obtained from all individual participants included in the study.

\section{RESULTS}

Of the 52 patients seen in follow-up, $67 \%$ were female and $33 \%$ were male. A total of $41 \%$ were atopic (Table 1). The characteristics of the four groups (broken down by patient-reported global assessment of improvement or worsening) are summarized in Table 2 . Nineteen percent of the patients were group 1 (no improvement or worse), $27 \%$ were group 2 (1-59\% improved), $25 \%$ were group 3 (60-99\%), and 29\% were group 4 (100\% improved).

\section{DISCUSSION}

This retrospective analysis has several interesting findings. First, $81 \%$ of patients report some sort of improvement, and $54 \%$ of patients report $>60 \%$ improvement. Second, females were more likely to have significant improvement. Seventy-nine percent of patients that improved (i.e., were in groups 2, 3 and 4) were female, whereas $80 \%$ of patients with no improvement (i.e., group 1) were males (Fisher's exact 0.01).

Notably, there does not appear to be a statistically significant relationship between a patient's number of positive allergens, the strength of positive patch test reactions, age, atopy, follow-up time or testing positive to a potentially systemic contact allergen ("systemic" was categorized as balsam of Peru, nickel, chrome and cobalt) and the patient's reported improvement.

Table 1 Patient demographics

\begin{tabular}{ll}
\hline Mean age & 48 \\
Sex & $67 \%$ female, 33\% male \\
Percent atopic & $41 \%$ \\
\hline
\end{tabular}


Table 2 Patient groups

\begin{tabular}{lllll}
\hline & $\begin{array}{l}\text { Group 1 (0\% } \\
\text { improvement or worse) }\end{array}$ & $\begin{array}{l}\text { Group 2 (15-60\% } \\
\text { improvement) }\end{array}$ & $\begin{array}{l}\text { Group 3 (65-89\% } \\
\text { improvement) }\end{array}$ & $\begin{array}{l}\text { Group 4 (100\% } \\
\text { improvement) }\end{array}$ \\
\hline Median age & 42.5 & 45.5 & 50.0 & 55.0 \\
Percent atopic & $30 \%$ & $50 \%$ & $38 \%$ & $40 \%$ \\
$\begin{array}{l}\text { Average \# } \\
\text { of }+ \text { allergens }\end{array}$ & 6.1 & 6.35 & 6 & 6 \\
\hline
\end{tabular}

\section{LIMITATIONS}

First, this is a retrospective cross-sectional analysis; therefore, causative relationships cannot be inferred. Second, not all patients patch tested at UCSF return for follow-up. Some patients return to their established dermatologists while others are lost to follow-up. There may be some bias toward patients who are doing better not returning for follow-up. Additionally, patients reporting worsening or no change in symptoms were classified as having $0 \%$ improvement. If they reported profound improvement and were completely clear on examination, they were classified as having $100 \%$ improvement. Moreover, this was not a blinded study, so patients may have overreported improvement at follow-up. As a result, the data may be skewed toward the extremes. We also do not know for certain if patients made any changes to other treatment regimens. Therefore, we cannot control for patients' use of topical steroids or other medications. In addition, these patients were all referred to a tertiary contact dermatitis clinic, and in that sense particularly symptomatic and insured patients may be overrepresented. In addition, this study captures patient-reported improvement only at one point in time. Future investigations could examine whether patients who return multiple times for follow-up after patch testing change their self-reported improvement over time. Although we focused in this study on patientreported improvement, future studies could investigate a physician's global assessment of patients to explore correlations between the two. Finally, the size of the database is small. As a result, we were not able to investigate factors such as individual allergens (even when we attempted to group these allergens into categories) or site of rash. Therefore, there may be relationships that we did not detect because of the small size of our database, and future studies could investigate even more patient characteristics, such as the duration of dermatitis and correlation of patient-reported metrics with investigator-reported metrics such as BSA.

\section{CONCLUSIONS}

The great majority of our patients, $81 \%$, reported improvement after patch testing. This is very encouraging as our patients who underwent patch testing with avoidance counseling benefited according to their own global assessment, which we believe is a powerful appraisal of both disease and symptom activity as well as quality of life. This study adds to the existing evidence suggesting that patients who are suspected of having ACD should be referred for patch testing and allergen avoidance counseling, as the majority of our patients demonstrated benefit. As previously discussed, using patient-reported data, like patients' global assessment of improvement, can give invaluable insight into the efficacy of therapeutic interventions for conditions like ACD. Our study provides supportive evidence that patch testing and allergen avoidance counseling, in cases of suspected ACD, can help patients improve their symptoms.

Past studies on the relevance of gender to outcomes in ACD have been inconclusive, and some have pointed to female gender predicting worse outcomes $[4,11]$. In stark contrast to 
what has been previously reported, women in our study reported more improvement than men. It is possible that women in this cohort adhered more closely to allergen avoidance regimens, or perhaps women received superior counseling. In addition, there may be some allergens that are more common in men that may be more difficult to avoid. Further studies are needed to elucidate the reason for improved outcome in women. The lack of relationship between concomitant diagnosis of atopic dermatitis or age and outcome supports findings from previous studies discussed in the introduction [4]. Overall, our results demonstrate that patients with varied characteristics benefit from patch testing and allergen avoidance counseling.

\section{ACKNOWLEDGEMENTS}

We thank the participants of this study.

Funding. We thank the UCSF Research Allocation Program for Trainees (RAPTr) for funding provided for this study. The processing charges were funded by Dr. Nina Botto and the University of California, San Francisco.

Authorship. All named authors meet the International Committee of Medical Journal Editors (ICMJE) criteria for authorship for this article, take responsibility for the integrity of the work as a whole and have given their approval for this version to be published.

Disclosures. Meredith S. Steuer and Nina C. Botto have nothing to disclose.

Compliance with Ethics Guidelines. All procedures performed in studies involving human participants were in accordance with the ethical standards of the institutional and/or national research committee and with the 1964 Helsinki Declaration and its later amendments or comparable ethical standards. Informed consent was obtained from all individual participants included in the study.
Open Access. This article is distributed under the terms of the Creative Commons Attribution-NonCommercial 4.0 International License (http://creativecommons.org/licenses/ by-nc/4.0/), which permits any noncommercial use, distribution, and reproduction in any medium, provided you give appropriate credit to the original author(s) and the source, provide a link to the Creative Commons license, and indicate if changes were made.

\section{REFERENCES}

1. Simpson EL, et al. When does atopic dermatitis warrant systemic therapy? Recommendations from an expert panel of the International Eczema Council. JAAD. 2017;77(4):623-33.

2. Linos E, Wehner MR, Frosch DL, Walter L, Chren MM. Patient-reported problems after office procedures. JAMA Intern Med. 2013;173(13):1249-50. https://doi.org/10.1001/jamainternmed.2013.1040.

3. Slevin ML, Plant H, Lynch $\mathrm{D}$, et al. Who should measure quality of life, the doctor or the patient? Br J Cancer. 1988;57:109.

4. Kadyk DL, McCarter K, Achen F, Belsito DV. Quality of life in patients with allergic contact dermatitis. J Am Acad Dermatol. 2003;49(6):1037-48.

5. Anderson RT, Rajagopalan R. Development and validation of a quality of life instrument for cutaneous diseases. J Am Acad Dermatol. 1997;37:41-50.

6. Rajagopalan R, Anderson R, Sarma S, Kallal J, Retchin C, Jones J, et al. An economic evaluation of patch testing in the diagnosis and management of allergic contact dermatitis. Am J Contact Dermatitis. 1998;9:149-54.

7. Rajagopalan R, Anderson R. Impact of patch testing on dermatology-specific quality of life in patients with allergic contact dermatitis. Am J Contact Dermat. 1997;8:215-21.

8. Eder L, Thavaneswaran A, Chandran V, Cook R, Gladman DD. Factors explaining the discrepancy between physician and patient global assessment of joint and skin disease activity in psoriatic arthritis patients. Arthritis Care Res. 2015;67:264-72.

9. Tabolli S, Bergama F, Alessandroni L, Di Pietro C, Sampogna F, Abeni D. Quality of life and psychological problems of patients with oral mucosal 
disease in dermatological practice. Dermatology. 2009;218:314-20.

10. Ramirez F, Chren M, Botto N. A review of the impact of patch testing on quality of life in allergic contact dermatitis. J Am Acad Dermatol. 2017;76:1000-4.

11. Skoet R, Zachariae R, Agner T. Contact dermatitis and quality of life: a structured review of the literature. Br J Dermatol. 2003;149:452-6.

12. Ayala F, Nino M, Fabbrocini G, Panariello L, Balato N, Foti C, Tosti A, Corazza M, Valsecchi RH, Gola M, Gallo R, Guarneri F, Pigatto PD, Cristaudo A, Schena D, Musumeci ML, Stingeni L, Lisi P. Quality of life and contact dermatitis: a disease specific questionnaire. Dermatitis. 2010;21(2):84-90.
13. Warshaw EM, Raju SI, Fowler JF Jr, et al. Positive patch test reactions in older individuals: retrospective analysis from the North American Contact Dermatitis Group, 1994Y2008. J Am Acad Dermatol. 2012;66:229-40.

14. Warshaw EM, Schram SE, Maibach HI, et al. Occupation-related contact dermatitis in North American health care workers referred for patch testing: cross-sectional data, 1998 to 2004. Dermatitis. 2008;19:261-74.

15. Warshaw EM, Ahmed RL, Belsito DV, et al. Contact dermatitis of the hands: cross-sectional analyses of North American Contact Dermatitis Group Data, 1994Y2004. J Am Acad Dermatol. 2007;57:301-14. 